\title{
Prevalence of Diabetic Retinopathy among Diabetics: A Hospital Based Study at Ashraff Memorial Hospital, Kalmunai
}

\author{
Mohammed Muzammil Al-Ameen Rizath', Jayasiri Deshapriya Dias², \\ Hameem Mohammed Ismy Mohammed', Mohamed Meerasahib Maroozathul Ilahi', \\ Athambawa Mohamed Razmy ${ }^{3}$ \\ ${ }^{1}$ Ashraff memorial Hospital, Kalmunai, Sri Lanka \\ ${ }^{2}$ Teaching Hospital, Batticaloa, Sri Lanka \\ ${ }^{3}$ Faculty of Applied Sciences, South Eastern University of Sri Lanka, Oluvil, Sri Lanka \\ Email: rizath@yahoo.com
}

Received 28 November 2015; accepted 13 December 2015; published 18 December 2015

Copyright (C) 2015 by authors and OALib.

This work is licensed under the Creative Commons Attribution International License (CC BY). http://creativecommons.org/licenses/by/4.0/

C. (i) Open Access

\begin{abstract}
Diabetic Retinopathy and diabetics are two highly associated severe diseases in human. This study assesses the risk of getting Diabetic Retinopathy among the Diabetic patients in the Kalmunai region. In this hospital based cross sectional study, all the diabetic patients who were attending to the diabetic clinic of the Ashraff memorial hospital from January 2014 to December 2014 were screened for Diabetic Retinopathy and their demographic details were recorded. Obtained information was analyzed for estimating the risk for Diabetic Retinopathy among the diabetic patients and it was estimated as $\mathbf{1 3 . 1 6 \%}$. No difference in risk of getting Diabetic Retinopathy was observed among different age group, educated level and gender. Risk of getting Diabetic Retinopathy increases with the increase of the duration suffered by the diabetic. The relative risk of getting Diabetic Retinopathy for patients with diabetic for more 12 years is 3.55 times greater compared to the fresh diabetic patients.
\end{abstract}

\section{Keywords}

Clinically Significant Macular Oedema, Diabetes Mellitus, Diabetic Retinopathy, Relative Risk

Subject Areas: Public Health

\section{Introduction}

Diabetic Retinopathy (DR) is strongly associated with both microvascular and macrovascular complications,

How to cite this paper: Rizath, M.M.A.-A., Dias, J.D., Mohammed, H.M.I., Ilahi, M.M.M. and Razmy, A.M. (2015) Prevalence of Diabetic Retinopathy among Diabetics: A Hospital Based Study at Ashraff Memorial Hospital, Kalmunai. Open Access Library Journal, 2: e2230. http://dx.doi.org/10.4236/oalib.1102230 
including retinopathy, nephropathy, and neuropathy and ischemic heart disease, peripheral vascular disease, and cerebrovascular disease, resulting in organ and tissue damage [1]. DR affects the peripheral retina, the macula, or both and is a leading cause of visual disability and blindness in people with diabetes [2]. The severity of DR ranges from nonproliferative and preproliferative to more severely proliferative DR, in which the abnormal growth of new vessels occurs [3]. Total or partial vision loss can occur through a vitreous hemorrhage or retinal detachment, and central vision loss can occur through retinal vessel leakage and subsequent macular edema [4]. The prevalence of DR increases with prolonged duration of diabetes [5]. It was found that at least some sort of DR will be detected in more than 75\% of diabetic population who had DM for more than 20 years duration [6]. A detail survey in the western countries confirmed that the DR is a leading cause of blindness in the western world and the impact of this much higher among the young people who are less than 40 years of age [7]. Further, DR is found to be a leading cause of new onset of blindness in many industrialized countries and more frequent cause of blindness elsewhere. The WHO estimation for global blindness depicts that DR is responsible for 4.8\% of 37 million cases of blindness throughout [8].

The seriousness of DR was not felt among the developing countries as a cause for the blindness because it was thought that retinal disease was an uncommon cause of blindness in the developing countries [9]. As a result, DR screening programmes were not included in the national programmes for prevention of blindness in the developing world. The risk for DR among the DM patients was estimated by different authors for different countries and those are listed in Table 1.

It can be observed that the South Asian countries have the higher risk for DR among the DM patients. In Sri Lanka, the risk is reported to be $31.3 \%$ but this figure must vary among the regions based on the socio economic conditions. Therefore this study was carried out to assess the risk for DR among the DM patients and to find out the associated factors relative to this risk.

\section{Methodology}

For this study, 772 diabetic patients who were attending to the diabetic clinic of the Ashraff Memorial Hospital, Kalmunai during the months from January 2014 to December

2014 were screened for DR. For screening, subjects were sent for vision test and pupil dilatation. Demographic data and clinical history of each patient was recorded in the structured manual. Both fundi were examined by the researchers at the slit lamp using the $+78 \mathrm{D}$ lens and looked for the findings of DR and Clinically Significant Macular Oedema (CSMO). The DR and CSMO were graded according to the standard classification of international clinical DR and macular oedema disease severity scales. When any one of the two eyes was having DR or CSMO, the subject was considered as having DR or CSMO. When both eyes are having two different grades of DR and CSMO, the worst grade of them was considered as the present condition in that subject. Then, actions were taken according to the findings. When the fundi were not visualized due to any other ocular pathology the subject was considered neither absent nor present of DR and CSMO. The collected data were analyzed to estimate the relative risk for demographic different factors by fitting logistic regression models using SAS software.

\section{Results and Discussion}

The risk for DR was estimated as $13.16 \%$ (95\% CI, 9.36\% and 16.96\%) among the DM patients in Kalmunai.

Table 1. Risk for DR among the DM patients in different regions.

\begin{tabular}{ccc}
\hline Country & Risk for DR (\%) & Age Groups Studied \\
\hline Australia & 22.2 & $\geq 40$ years \\
USA & 33.2 & $45-85$ years \\
Finland & 21.0 & $\geq 70$ year \\
Oman & 14.4 & All age groups \\
India & 34.0 & All age groups \\
Pakistan & 33.3 & All age groups \\
Sri Lanka & 31.3 & All age groups \\
\hline
\end{tabular}

Sources: [3] [10]-[19]. 
The prevalence of CSMO was 7.9\%. Among the DR patients, there were mild DR (79.93\%), moderate DR (10.03\%), sever DR (2.5\%) and extreme DR (7.52\%) categories. A Past Sri Lankan study reported the risk for DR was 31.3\% [19] in the diabetic clinics, which is too greater than the results obtained in this study. This variation may be due to the socio economic conditions and age variations of the patients. However this results is closer to the risk reported in a hospital based study of Oman which is $14.39 \%$ [3].

The mean age of this studied sample was 52.6 years which is closely tally with United Kingdom study's [13] mean age of 54 years. But the risk for DR in United Kingdom study was 52.91\% for all ages which is greater compare to this study. But the variation of the age groups has to be considered before making such comparison. Figure 1 shows the prevalence percentage DR among the DM patients for different age levels.

The risk for DR for different age groups was compared basically with $\leq 40$ years age group. The odd ratios for $40-60$ and $\geq 60$ age groups were 1.49 (95\% CI, 0.33, 6.82) and $2.56(95 \%$ CI, $0.55,11.96)$ respectively. Even though there was an increase in risk with age, the logistic regression shows there is no significant difference in risk for DR between different age groups $(P=0.238)$.

The relative risk for DR was not significantly differs for gender $(P=0.144)$ and $18.3 \%$ of the male and $11.8 \%$ of the female DM patients had DR. In this study the response rate of females was higher than males and the same results were obtained in this kind of studies of Pakistan and Paraguay [13] [17] but the prevalence of DR was $33.3 \%$ and $48.53 \%$ respectively for male and female.

Among the Diabetic patients, $97.69 \%$ of patients had Type-II and the rest, had Type-I diabetic. There was no significant relationship noted between the prevalence of DR and type of DM $(P=0.82)$. This association was not established because most of the patients had Type-2 diabetic. A slight increasing risk for DR is visible with increasing education level and it is shown in Figure 2. However this increasing risk is not statistically significant $(P=0.25)$.

Risk of getting DR is increasing with the duration of DM a patient had $(P=0.004)$. The relative risk of getting DR for patients with diabetic for more than 12 years is 3.55 times greater compare to the patients with diabetic for less than 12 years (95\% CI, 1.56, 8.11). Figure 3 shows the relationship between the risk for DR and the duration suffered with DM.
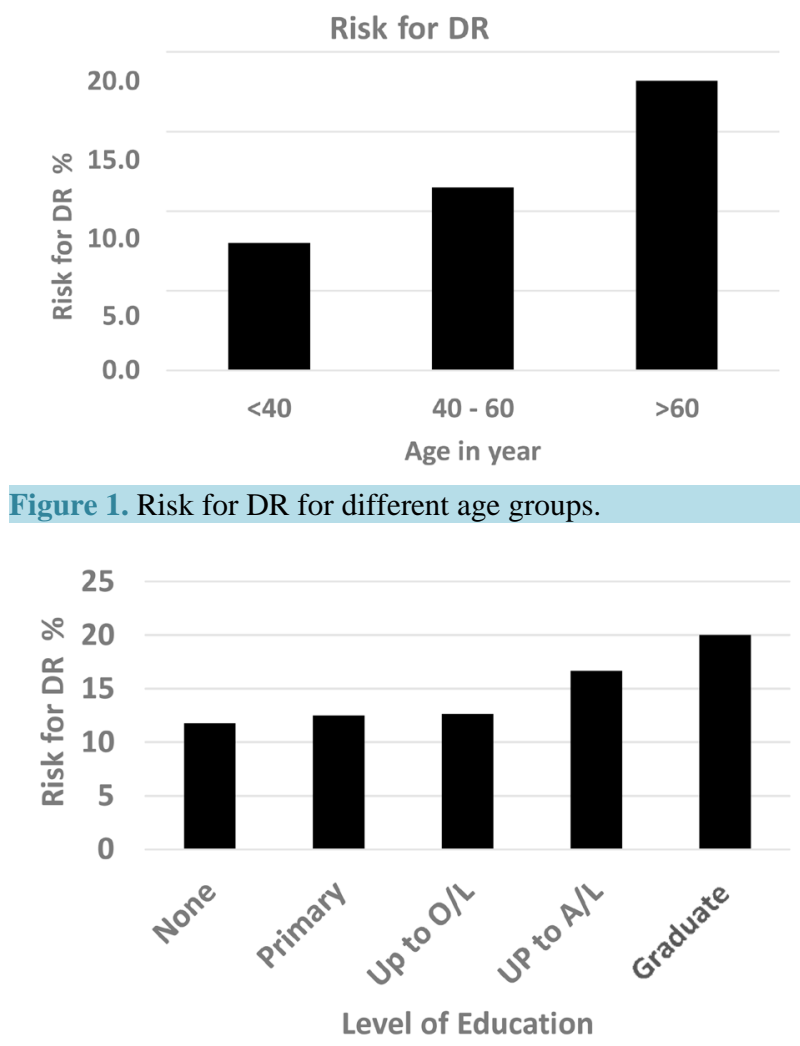

Figure 2. Risk for DR for educational levels. 


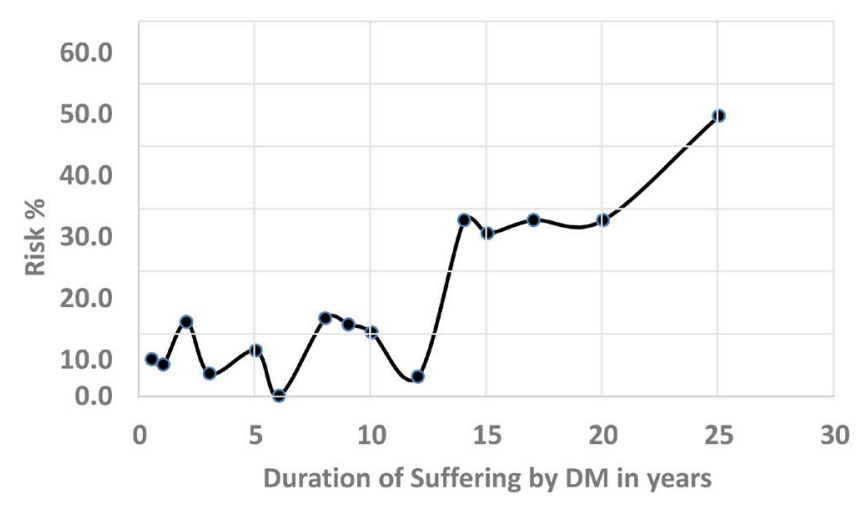

Figure 3. Risk for DR and duration suffering with DM.

\section{Conclusion}

The risk for DR among the DM patients in the studied region is less compared to other regions. But it is believed that the prevalence DM higher in the studied region and therefore considering the severity of the DR and its' consequences, educating people on DR is essential. A sudden high risk of DR for the patients with more than 12 years DM is a significant finding, and a special mechanism has to be setup for this group for preventing blindness. Currently there are two methods available for preventing blindness from DR in patients with DM. Those are better control of blood sugar level and regular screening to detect early for treatment to prevent complications. The diabetics control and complications trials have proved that better control of blood sugar levels slows the onset and progression of DR. Better control also reduces the need for sight-saving laser surgery.

\section{References}

[1] Anonymous (1991) UK Prospective Diabetes Study VII (UKPDS). VIII. Study Design, Progress and Performance. Diabetologia, 34, 877-890.

[2] Todd, W.C. (2008) Diabetes-Related Micro Vascular and Macro Vascular Diseases in the Physical Therapy Setting. Journal of the American Physical Therapy Association, 88, 1322-1355.

[3] Khandkar, R., Al-Lawatii, J., Mohammed, A.J. and Al-Raisi, A. (2003) Diabetic Retinopathy in Oman: A Hospital Based Study. British Journal of Ophthalmology, 87, 1061-1064. http://dx.doi.org/10.1136/bjo.87.9.1061

[4] Dandora, L., Dandora, R., Naduvilath, T.J., McCarty, C.A. and Rao, G.N (1999) Population Based Assessment of Diabetic Retinopathy in Urban Population in Southern India. British Journal of Ophthalmology, 83, 937-940. http://dx.doi.org/10.1136/bjo.83.8.937

[5] Rema, M., Deepa, R. and Mohan, V (2000) Prevalence of Retinopathy at Diagnosis among Type 2 Diabetic Patients Attending a Diabetic Centre in South India. British Journal of Ophthalmology, 84, 1058-1060. http://dx.doi.org/10.1136/bjo.84.9.1058

[6] World Health Organization (2005) Prevention of Blindness from Biabetes Mellitus. Report of a WHO Consultation in Geneva, Switzerland, 9-11 November 2005, 48 p.

[7] Hoogwerf, B.J. (2005) Complications of Diabetes Mellitus. International Journal of Diabetes in Developing Countries, 25, 63-69. http://dx.doi.org/10.4103/0973-3930.22774

[8] Resnikoff, S., Pascolin, D., Etya ale D., Kocur, I., Pararajasegaram, P. and Pokharel (2004) Global Data on Visual Impairment in the Year 2002. Bulletin of World Health Organization, 82, 844-851.

[9] Yorston, D. (2003) Retinal Diseases and Vision 2020. Journal of Community Eye Health, 16, 19-20.

[10] Mckay, R., McCarty, C.A. and Taylor, H.R. (2000) Diabetic Retinopathy in Victoria, Australia: The Visual Impairment Project. British Journal of Ophthalmology, 84, 865-870. http://dx.doi.org/10.1136/bjo.84.8.865

[11] McCarty, C.A., Smith, C.W.L., Lee, S.E., Livingstio, P.M., Stanislavisky, Y.L. and Taylor, H.R. (1998) Use of Eye Care Services by People with Diabetes: The Melbourne Visual Impairment Project. British Journal of Ophthalmology, 82, 410-414. http://dx.doi.org/10.1136/bjo.82.4.410

[12] Wong, T.Y., Klein, R., Islam, A., Cotch, M.F., Folsom, A.R. and Klein, B.E.K. (2006) Diabetic Retinopathy in Multi Ethnic Cohort in the United States. American Journal of Ophthalmology, 141, 446-455. http://dx.doi.org/10.1016/j.ajo.2005.08.063 
[13] Smith, T.S.T., Szetu, J. and Bourne, P.R.A. (2007) The Prevalence and Severity of Diabetic Retinopathy, Associated Risk Factors and Vision Loss in Patient Registered with Type 2 Diabetes, Luganville Vanuatu. British Journal of Ophthalmology, 91, 415-419. http://dx.doi.org/10.1136/bjo.2006.104174

[14] Hirvella, H. and Laatikainen, L. (1997) Diabetic Retinopathy in People Aged 70 Years or Older: The Oulu Eye Study. British Journal of Ophthalmology, 81, 214-217. http://dx.doi.org/10.1136/bjo.81.3.214

[15] Rema, M., Deepa, R. and Mohan, V. (2000) Prevalence of Retinopathy at Diagnosis among Type 2 Diabetic Patients Attending a Aiabetic Centre in South India. British Journal of Ophthalmology, 84, 1058-1060. http://dx.doi.org/10.1136/bjo.84.9.1058

[16] Narendran, V., John, R.K., Raguram, A., Ravindran, R.D., Nirmalan, P.K. and Thulasiraj, R.D. (2002) Diabetic Retinopathy among Self Reported Diabetics in Southern India, A Population Based Study. British Journal of Ophthalmology, 86, 1014-1018. http://dx.doi.org/10.1136/bjo.86.9.1014

[17] Agrawal, R.P., Ranka, M., Beniwal, R, Gothwal, S.R. and Jain, G.C. (2003) Prevalence of Diabetic Retinopathy in Type 2 Diabetes in Relation to Risk Factors, Hospital Based Study. International Journal of Diabetes in Developing Countries, 23, 16-19.

[18] Sunil, G. and Ajay, A. (2004) Prevalence of Diabetic Retinopathy and Influencing Factors among Type 2 Diabetics from Central India. International Journal of Diabetes in Developing Countries, 24, 75-78.

[19] Fernando, D.S.J., Sirbadana, S.H., Silva, D. and Suabasinhe, Z. (1993) Prevalence of Diabetic Retinopathy in Sri Lankan Diabetic Clinic. Ceylon Medical Journal, 38, 120-123. 